\title{
Immunoprotective Sertoli cells: making allogeneic and xenogeneic transplantation feasible
}

\author{
Payal Mital, Gurvinder Kaur and Jannette M Dufour \\ Cell Biology and Biochemistry, Texas Tech University Health Sciences Center, 3601 4th Street, \\ Stop 6540, Lubbock, Texas 79430, USA
}

Correspondence should be addressed to J M Dufour; Email: jannette.dufour@ttuhsc.edu

P Mital and G Kaur contributed equally to this work

\begin{abstract}
The testis as an immune-privileged site allows long-term survival of allogeneic and xenogeneic transplants. Testicular Sertoli cells (SCs) play a major role in this immunoprotection and have been used to create an ectopic immune-privileged environment that prolongs survival of co-transplanted allogeneic and xenogeneic cells, including pancreatic islets and neurons. Extended survival of such grafts testifies to the immunoprotective properties of SCs. However, there is still variability in the survival rates of the co-grafted cells and rarely are $100 \%$ of the grafts protected. This emphasizes the need to learn more about what is involved in creating the optimal immunoprotective milieu. Several parameters including organization of the SCs into tubule-like structures and the production of immunomodulatory factors by SCs, specifically complement inhibitors, cytokines, and cytotoxic lymphocyte inhibitors, are likely important. In addition, an intricate interplay between several of these factors may be responsible for providing the most ideal environment for protection of the co-transplants by SCs. In this review, we will also briefly describe a novel use for the immune-privileged abilities of SCs; engineering them to deliver therapeutic proteins for the treatment of diseases like diabetes and Parkinson's disease. In conclusion, further studies and more detailed analysis of the mechanisms involved in creating the immune-protective environment by SCs may make their application in co-transplantation and as engineered cells clinically feasible.

Reproduction (2010) 139 495-504
\end{abstract}

\section{Introduction}

Transplantation as a means of replacing diseased tissue after organ failure has therapeutic potential as a treatment for many disorders, such as diabetes and Parkinson's disease. However, chronic immunosuppression, needed to prevent tissue rejection, makes the wide spread application of transplantation difficult because of the serious side effects of immunosuppressants. One possible way to prevent tissue rejection and eliminate the need for continuous immunosuppression may be to use immune-privileged sites or their associated tissues. Immune-privileged sites are places in the body where foreign tissue grafts can survive for extended periods of time because immune surveillance is attenuated, and thus foreign antigens can be tolerated without evoking a detrimental immune response (Barker \& Billingham 1977).

The testis is considered an immune-privileged site, and testicular Sertoli cells (SCs) have been identified as key players for conferring this immune privilege (Selawry 1994, Dufour et al. 2003 b). Consequently, the ability of SCs to modulate immune responses has been studied by co-transplanting them with other cells at non-immuneprivileged, ectopic sites, where SCs were found to protect and extend survival of such grafts (Dufour et al. 2003 b). In this review, we describe: 1) co-transplantation experiments that were performed with SCs, 2) several of the possible mechanisms involved in SC modulation of the immune response, and 3) alternative strategies for utilization of these very unique properties of SCs.

\section{Sertoli cell co-transplantation}

\section{Sertoli cells and testicular immune privilege}

The testis is a highly specialized organ developed specifically for the production of spermatozoa and male sex hormones (Russell et al. 1990). Morphologically, it consists of convoluted seminiferous tubules (site of spermatogenesis) separated by the interstitium (site of testosterone production). The seminiferous tubules are composed of SCs and germ cells surrounded by a layer of peritubular myoid cells. The interstitium contains Leydig cells, blood vessels, macrophages, lymphocytes, and fibroblasts. 
The immunologically privileged status of the testis has been appreciated for many years from studies of allogeneic (between genetically different individuals of the same species) and xenogeneic (between individuals of different species) transplantation of tissues, which survived for various lengths of time following engraftment into the testes of small and large animals. The tissues grafted include skin (Whitmore \& Gittes 1977, Head et al. 1983a), parathyroid fragments (Naji \& Barker 1976, Head et al. 1983a, Head \& Billingham 1985, Whitmore et al. 1985), pancreatic islets (Ferguson \& Scothorne 1977a, 1977b), and insulinomas (Akimaru et al. 1981). These studies demonstrated that the environment of the testis could protect allogeneic and xenogeneic grafts from immune destruction. In an attempt to identify the mechanism responsible for the immunoprotective properties of the testis, the cellular components and physiological conditions of the testes were examined. The initial hypothesis was that the lower temperature of the scrotum (Selawry \& Whittington 1984, Head \& Billingham 1985) and impaired lymphatic drainage (Head et al. 1983b, Head \& Billingham 1985) were responsible. However, when the testis was placed into the abdominal cavity, it maintained the ability to protect transplanted cells. Likewise, examination of the lymphatic drainage from the testis demonstrated that it was fully functional. Furthermore, selective depletion of Leydig cells (Selawry \& Whittington 1988, Cameron et al. 1990) and germ cells (Selawry \& Whittington 1984, Whitmore et al. 1985) failed to prevent the immunoprotection of allografts when transplanted into the testes. These results suggested that the remaining cellular components of the testis, the majority of which were SCs, were primarily responsible for the successful survival and function of the transplanted tissues.

SCs comprise a major component of the mammalian testis, and are considered 'nurse' cells because they provide numerous factors required for the orderly development and protection (i.e. immune privilege) of the maturing germ cells (Griswold 1998). They are columnar cells that extend from the outer edge of the seminiferous tubules toward the lumen, completely surrounding the developing germ cells. Adjacent SCs form tight junctions with one another creating a physical barrier that separates the germ cells localized toward the lumen from the blood supply (Dym \& Fawcett 1970, Russell 1977). This barrier, the so-called blood-testis barrier, allows the SCs to control and regulate the milieu of the developing germ cells and, along with the secretion of immunomodulatory factors, creates an effective immuneprivileged environment. These immune-privileged properties are critical for the protection of the developing germ cells because cell surface markers on the germ cells can be recognized as foreign by the host immune system (O'Rand \& Romrell 1977, Tung \& Fritz 1978). Without the ability of the immune system to tolerate their existence, the germ cells would be recognized as foreign and subjected to immunologic attack. These unique immune-privileged properties of SCs have led to the idea that SCs could be used for the protection of non-testicular cellular grafts in transplantation.

\section{Co-transplantation of immune-privileged Sertoli cells with pancreatic islets}

Evidence for the immunoprotective capabilities of SCs was first provided by studies in which allogeneic SC-enriched fractions were co-grafted with allogeneic islets of Langerhans underneath the kidney capsule (Selawry \& Cameron 1993). It was found that SCs had the ability to protect islet allografts even in an ectopic site. However, a 3-day course of cyclosporine for immune suppression immediately post transplantation was required for extended survival of islet allografts. In this study, $>75 \%$ of the co-grafted animals remained normoglycemic, with blood glucose levels within the normal range, for over 100 days, while none of the animals receiving islets alone became normoglycemic. The results were comparable in male and female recipients and did not interfere with the ability of female recipients to conceive and carry pregnancies to full term. Korbutt et al. (1997) confirmed and extended these results by modifying the method for isolating and culturing the SCs. These improvements led to the survival of $100 \%$ of the islet allografts for at least 100 days without the requirement of immunosuppression.

Subsequent experiments demonstrated that SCs can protect islets from autoimmune destruction (Korbutt et al. 2000, Suarez-Pinzon et al. 2000) and xenogeneic rejection (Yang \& Wright 1999, Luca et al. 2001, Dufour et al. 2003a). In the autoimmune studies, syngeneic (transplantation between genetically identical individuals of the same species) SCs and islets were transplanted under the kidney capsule of non-obese diabetic (NOD) mice. NOD mice were used as a model of type 1 diabetes mellitus in which syngeneic islets are destroyed by an autoimmune mechanism. All recipient mice receiving islets only rejected the grafts and returned to the diabetic state within 14 days (Korbutt et al. 2000, Suarez-Pinzon et al. 2000). In contrast, in mice receiving both SCs and islets, the graft survival was significantly prolonged with $40-64 \%$ of mice remaining normoglycemic for 60 days after transplantation (Korbutt et al. 2000, Suarez-Pinzon et al. 2000).

As for the protection of xenogeneic islet grafts, three initial reports demonstrated the survival of fish (Yang \& Wright 1999) and rat (Luca et al. 2001, Dufour et al. 2003a) islets after co-transplantation with SCs into diabetic mice. In each case, there was a significant prolongation of islet graft survival when co-transplanted with SCs compared with islets engrafted alone. However, in all cases, this required the combination of SCs and the use of encapsulation (Yang \& Wright 1999, Luca et al. 2001) or a short course of immunosuppression 
(Dufour et al. 2003a). For example, when syngeneic mouse SCs were co-engrafted with rat islets in diabetic mice that received one injection of anti-lymphocyte serum (ALS), there was a significant prolongation in mean graft survival time, with $32 \%$ of recipients remaining normoglycemic for over 75 days (Dufour et al. 2003a). In contrast, when the rat islets were transplanted alone or in combination with either SCs or ALS, all the grafts were rejected within 18 days of transplantation. Consequently, these studies suggest that SCs have potential to protect transplanted tissue grafts, a prominent model being islet transplantation to treat type I diabetes.

\section{Co-transplantation of Sertoli cells with other tissues}

The ability of SCs to protect co-grafted cells is not limited to islets of Langerhans. SCs have also been shown to prolong survival of xenogeneic adrenal chromaffin cells (Sanberg et al. 1996), xenogeneic neurons (Willing et al. 1999), xenogeneic liver cells (Rahman et al. 2005), allogeneic and xenogeneic skin grafts (Shamekh et al. 2006, Lee et al. 2007a), and allogeneic heart grafts (Lim et al. 2009). The first report of SCs protecting other cells besides islets was by Sanberg et al. (1996), where they co-transplanted rat SCs with bovine adrenal chromaffin cells into the rat brain. The authors found that when the chromaffin cells were co-grafted with SCs, both cell types were present in the grafts for at least 2 months, whereas no chromaffin cells were detected when transplanted alone. In a subsequent study, the same group demonstrated survival of human neuron-like cell grafts for 3 months when co-transplanted with SCs into the striatum of rats (Willing et al. 1999). In both the studies, grafts containing SCs resulted in a significant decrease in the immune response to the transplanted cells, as measured by a reduced microglial response (Sanberg et al. 1996, Willing et al. 1999).

Similarly, SCs protected human liver cells. In this case, when SCs co-encapsulated with human hepatocytederived cell line (HepG2) cells in alginate poly-L-lysine beads were injected i.p. into normal rats or rats with acute hepatic failure HepG2 cells were recovered after 1 month (Rahman et al. 2005). In contrast, when HepG2 cells were transplanted in beads without SCs, HepG2 cells were either not detected as was the case in the acute hepatic failure rats or very few cells surrounded by an intense infiltrate were recovered from normal rats (Rahman et al. 2005).

Some recent and intriguing reports have indicated that systemic tolerance can be induced after i.v. (Shamekh et al. 2006) or i.p. (Lee et al. 2007a, Lim et al. 2009) injection of SCs. A significant prolongation in the survival of skin (Shamekh et al. 2006, Lee et al. 2007a) and heart (Lim et al. 2009) grafts was observed in mice that had received an injection of SCs. This is different from the previous studies, where SCs were co-transplanted with the protected allogeneic or xenogeneic tissues. All of these studies clearly show that SCs play an important role in the creation of an immune-privileged environment within the testis. Moreover, SCs are capable of retaining these immunoprotective properties outside of the testis by creating an immune-privileged ectopic site.

\section{Transplantation in large animal models}

Earlier studies performed in rodent models demonstrate SCs are immunoprotective. In order to use this for clinical application, the immune-privileged ability must first be tested in large animal models. Initially, the immunoprotective capability of testes in large mammals was examined. Using a non-human primate model, Selawry et al. demonstrated the survival of allogeneic islets after transplantation into testes, which had been repositioned in the abdominal cavity of three male diabetic rhesus monkeys (Selawry 1994; reviewed in Dufour et al. 2003 b). Each animal received a brief immunosuppressive regimen, and the monkeys remained normoglycemic for 8,54 , and 60 months after transplantation. In the monkey that remained normoglycemic for 60 months, a bilateral orchiectomy was performed which produced a rapid reversion to the diabetic state. Histological examination of the graft site in this animal revealed the presence of well-granulated, viable islets and an absence of inflammation in the transplant area.

Additionally, porcine islet xenografts were found to survive in the testes of beagle dogs (Gores et al. 2003). In this study, neonatal porcine islets were added to the cryptorchid testes or the liver. One set of dogs received a minimal course of immunosuppression. A separate set of dogs with islets transplanted into the testes did not receive any immunosuppression. The grafts were collected after 100 days, and immunohistochemistry was performed to identify surviving islets. In all of the animals with islets transplanted into the testis, abundant viable islet cells were detected with no difference in islet survival between animals receiving immunosuppression and those that did not. No evidence of lymphocytic infiltration was seen within these grafts. In contrast, islets were not detected in the group transplanted to the liver. These results indicated that testes in large animals maintain their immune-privileged abilities when injected with foreign cells similar to testes of smaller mammals.

More recently, the immunoprotective ability of neonatal porcine SCs was examined in non-human primates. Neonatal porcine SCs were transplanted with neonatal porcine islets into non-diabetic macaques (Wang et al. 2005). The porcine cells were transplanted into the omental pouch, kidney, pancreas, and liver. Survival was examined histologically 2 months post engraftment and, while some glucagon (a marker for islet $\alpha$ cells) and inhibin (a marker for SCs) immunoreactive 
cells were found, no insulin (a marker for islet $\beta$ cells) positive cells were detected (Wang et al. 2005). Thus, it was concluded in this model that SCs had limited ability to protect the islet grafts.

\section{Clinical transplantation of porcine Sertoli cells}

The survival and immunoprotective capability of SCs isolated from neonatal pigs has also been examined after transplantation in humans. Albeit controversial, SCs were co-transplanted with islets as a treatment for patients with type I diabetes (Valdes-Gonzalez et al. 2005, 2007). A stainless steel wire mesh chamber was placed subcutaneously into the abdominal region of insulin-dependent adolescents (11-17 years old; Valdes-Gonzalez et al. 2005, 2007). Two months later, neonatal porcine SCs were mixed with neonatal porcine islets and placed into this chamber. The chambers were pre-implanted in order to create a vascularized collagen site for subsequent transplantation. They were porous and did not prevent the entry of infiltrating host blood vessels or cells associated with the immune system. The patients did not receive any immunosuppressive treatment. The results indicated that 6 of the 12 patients experienced significant reductions in exogenous insulin requirements lasting for at least 4 years post transplant, while maintaining stable or improved $\mathrm{HbAlc}$ levels. Moreover, two patients experienced periods of insulin independence of up to 2 months. In the patients who were tested, porcine insulin was detected by HPLC at 28 months $(n=1)$ and 4 years $(n=2)$ post transplant. However, porcine C-peptide, a molecule produced during insulin synthesis and considered a definitive marker of insulin production, was not detectable at levels that would suggest a functional islet graft. Histological analysis was performed on grafts removed from four patients after 3 years, and insulin and glucagon positive islet cells and mullerian inhibiting substance (a marker for SCs) positive SCs were identified within the grafts. The same group reported similar results in a more recent case, where an 18-year-old woman received an analogous transplant regimen (Valdes-Gonzalez et al. 2007).

The results from the large animal studies are encouraging and suggest the testes of large animals are immune-privileged sites, but yet the use of SCs from higher mammals has had limited success. This emphasizes the need to explore alternative approaches and to study the factors produced by SCs potentially responsible for the immunoprotection.

\section{Mechanism for Sertoli cell immune privilege}

\section{Parameters enhancing Sertoli cell protection}

Several parameters could influence the success of SC transplantation. For instance, optimal protection of islets was found to be highly dependent on the number of SCs co-engrafted, with low or high doses of SCs resulting in rejection of the transplanted islets, and an intermediate dose leading to a significant prolongation of islet graft survival (Korbutt et al. 1997, Takeda et al. 1998, Dufour et al. 2008a, 2008b). Additionally, the age of the SC donor could affect the outcome. The majority of the studies described above with successful protection of co-transplanted cells used SCs isolated from pubertal or adult testes, not neonatal testes, suggesting mature SCs are needed for optimal protection. While intriguing, a direct comparison of the immunoprotective ability of SCs isolated from various ages from the same species has never been tested. Another parameter that may play a role is the purity of the isolated SC preparations. In the studies reporting SC purity, it varied from 70 to $95 \%$ with most of the contaminating cells being peritubular myoid cells and germ cells. The importance of these other testicular cells remains to be examined.

Recently, we have found that there was a correlation between the formation of tubule-like structures by the transplanted SCs and the successful survival of the co-transplanted islets (Dufour et al. 2008b). In the successful grafts, the islets were located near SCs that were arranged in tubule-like structures (Fig. 1), while in the unsuccessful grafts, the SCs were aggregated in cell clusters or arranged randomly and lacked well-organized tubule structures. The tubule structures found in the successful grafts resembled those found in testes deficient of germ cells, with the SC nuclei located along the basal edge of the tubules (Fig. 1C) surrounded by a layer of peritubular cells. Perhaps, the arrangement of the transplanted cells in these tubule structures is important because it allows the SCs to organize into a polarized
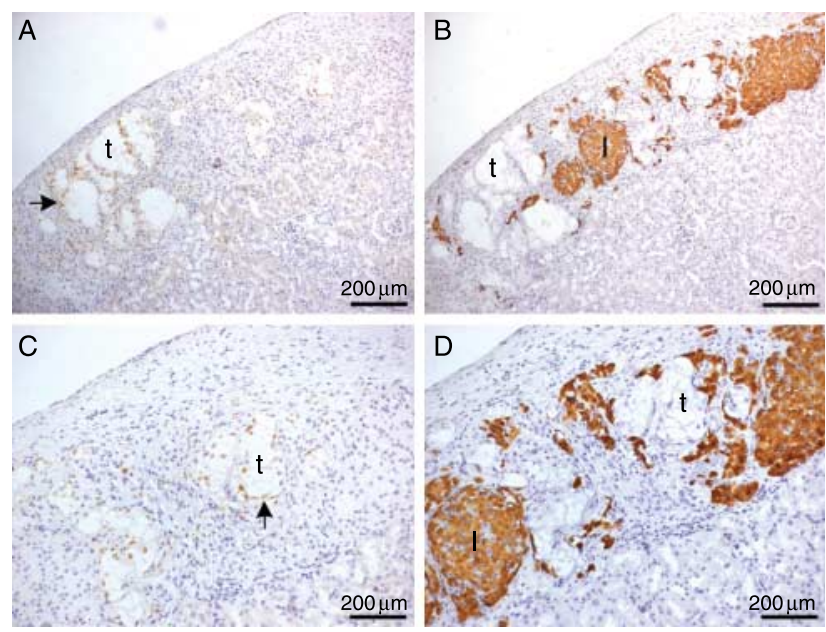

Figure 1 Successful co-transplantation of allogeneic islets and Sertoli cells. Four million BALB/C SCs were co-transplanted with $500 \mathrm{BALB} / \mathrm{C}$ islets under the kidney capsule of a diabetic CBA/J mouse (A-D). The graft was collected from a normoglycemic mouse at 101 days post transplant, and tissue sections were immunostained for GATA-4 (A and C; SC marker) and insulin (B and D; islet cell marker). All sections were counterstained with hematoxylin. t, Tubule-like structure; I, islet; arrow, SC nucleus. 
epithelial layer. This layer could lead to the formation of tight junctions and other interactions between adjacent cells, thereby establishing communications and modifying the secretion of factors. Ultimately, through this cross-talk, an immunoprotective microenvironment might be created. In support of this, one of the improvements made by Korbutt et al. which may have led to their increased success was the addition of a 48-h culture period prior to transplantation. They found that during this culture period the isolated SCs formed cellular aggregates, which contained tight junctions between adjacent SCs (Korbutt et al. 1997). Similar to their arrangement in the native testis, SCs located within the tubules were polarized with an apical-basal orientation. Many in vitro studies have shown that this orientation alone can alter many of the factors secreted by SCs when compared to randomly arranged SCs (Russell \& Griswold 1993). Thus, formation of tubule structures by the SCs indicates the existence of a more physiological state, and this could be related to survival of the co-transplanted cells.

SC/islet co-transplantation studies also provide evidence against the common belief that germ cells in the testis are protected only because they are sequestered behind the SC tight junctions, the so-called blood-testis barrier. In the successful transplants, the majority of the islets were located outside of the tubule structures (Fig. 1) and not within the lumen, as would be expected if the physical barrier created by the Sertoli-Sertoli tight junctions was the reason for this protection (Dufour et al. 2008b). Additional support that immune privilege in the testis is more complex is based on the extended survival of foreign tissue engrafted into the interstitium of the testis (reviewed in Dufour et al. (2003b)). Furthermore, spermatogonia, which are located along the basal edge of the seminiferous tubules outside of the Sertoli-Sertoli tight junctions, have been shown to be immunogeneic and yet are not attacked by the immune system (Yule et al. 1988). This suggests the factors secreted by SCs are important for the protection of the co-grafted cells and creation of the testicular immuneprivileged environment.

\section{Production of immunoprotective factors by Sertoli cells}

Several in vitro cell culture experiments have demonstrated that SCs secrete molecules that inhibit the proliferation of both B and T lymphocytes (Wyatt et al. 1988, Selawry et al. 1991, De Cesaris et al. 1992). Moreover, detailed analysis of the cellular infiltrate in rejected SC/islet co-grafts, using selective markers for the different immune cells, revealed the presence of high numbers of CD4 T-cells, CD8 T-cells, and macrophages (Dufour et al. 2008b). On the other hand, in the successful grafts fewer CD4 T-cells and macrophages and very few CD8 T-cells were detected (Dufour et al. 2008b). The mechanisms responsible for these effects are unknown, but it is likely that the factors expressed by SCs, which can inhibit the innate and adaptive immune responses, are involved. Molecules that may modulate the humoral and cell-mediated effector mechanisms of the immune response will be discussed below.

\section{Sertoli cell influence on T-cell responses}

Cultured SCs have been shown to secrete factors that inhibit T-cell proliferation by arresting them in $\mathrm{G}_{1}$ phase of the cell cycle (Wyatt et al. 1988, Selawry et al. 1991, De Cesaris et al. 1992). The blockade of lymphocyte proliferation was associated with a decrease in the production of interleukin-2 (IL2), which could not be overcome with the addition of exogenous IL2 suggesting that some unidentified factor(s) secreted by the SCs suppressed both IL2 production as well as the responsiveness of the lymphocytes to exogenous IL2 (Selawry et al. 1991, De Cesaris et al. 1992).

Intravenous or intraperitoneal injection of SC led to prolonged survival of skin (Shamekh et al. 2006, Lee et al. 2007a) and heart (Lim et al. 2009) grafts. In one case, the injected SCs migrated into the mesenteric lymph nodes and spleen (Lee et al. 2007a), suggesting that SCs may induce systemic immune tolerance through direct interaction with the recipient's immune cells within the lymphoid organs. This is further supported since, as compared to mice that did not receive SCs, lymphocytes isolated from spleens from mice that had been injected with SCs were found to have a significant decrease in proliferation rate after stimulation with allogeneic or xenogeneic cells. Additionally, the phenotype of the isolated splenocytes and the plasma cytokine levels were altered with a significant decrease in the number of CD4/CD25 double positive cells (Lim et al. 2009) and plasma IL1B, IL2, and IL6 levels (Shamekh et al. 2006).

However, it should be noted that Korbutt et al. (1997) did not observe tolerance induction with their model. SC and islets were co-transplanted underneath the left kidney capsule, and 100 days after transplantation the grafts were removed from normoglycemic rats. Allogeneic islets were then transplanted alone underneath the right kidney capsule of the same rats that had returned to the diabetic state. These rats rejected the new islet grafts within an average of 10 days. The differences observed between these studies may be due to the method of transplantation, i.e. i.v. or i.p. injection versus co-transplantation underneath the kidney capsule and suggest SC injection combined with SC co-transplantation could allow for prolonged graft survival and tolerance induction.

Further modification of the immune response was shown by Suarez-Pinzon et al. (2000). As described above, transplantation of syngeneic SCs and islets into NOD mice prolonged islet graft survival. In successful mice, SCs within the grafts maintained high transforming growth factor $\beta$ (TGFB) expression throughout the 
experiment (60 days) and plasma TGFB levels were elevated approximately twofold. The protective effect of SCs on islet graft survival was blocked after treatment with an anti-TGFB antibody and destruction of the islet grafts was associated with an increase in interferon $\alpha$ (IFNA)-producing cells and a decrease in IL4-producing cells. This modulation in cytokine levels after anti-TGFB antibody administration suggests TGFB production by SCs may act on the infiltrating cells to induce their differentiation into a Th2 (protective) over Th1 (destructive) response. Thus, it appears SC can modify the T-cell response by production of immune-regulating factors and possibly through direct interaction with immune cells at the graft site, spleen, and lymph nodes.

\section{Resistance to complement-dependent, antibody-mediated cytolysis}

Antibody-mediated activation of the complement cascade in response to transplanted tissue can lead to cell lysis through formation of the membrane attach complex (MAC). SCs are resistant to killing by this mechanism since they survive both when transplanted as discordant xenografts (Dufour et al. 2003c, Gores et al. 2003), which by definition indicates the presence of antibodies directed against the transplanted tissue, and when subjected to a human antibody/complementmediated killing assay (Dufour et al. 2005).

For example, neonatal porcine SCs were found to survive throughout the study (at least 42, 90, and 30 days respectively) when transplanted into mice, rats, and dogs (Dufour et al. 2003c, Gores et al. 2003). No immunosuppression was used in the rodent recipients, while a 10-day course of immunosuppression was used in the dogs. Since transplantation of porcine cells into rodents and dogs is considered discordant xenotransplantation, this suggests the cells were able to survive both humoral and cell-mediated rejection.

Additionally, neonatal porcine SCs were resistant to an in vitro hyperacute rejection assay. SCs were exposed to human serum followed by the addition of rabbit complement and analyzed for survival. While human $\operatorname{IgG}$ and $\operatorname{lgM}$ antibodies were able to bind to the SCs and activate the complement cascade, the cells were not lysed and the MAC was not formed (Dufour et al. 2005). Inhibition of the complement cascade may be due to the production of complement inhibitors by SCs as they have been shown to express membrane cofactor protein, decay accelerating factor, CD59, and clusterin (Bailey \& Griswold 1999, Mead et al. 1999, Lee et al. 2007b).

\section{Resistance to granzyme-mediated and Fas-Fas ligand apoptosis}

CD8 T-cells and natural killer cells are the main cytotoxic lymphocytes that induce apoptosis of grafted cells. Target cell killing is through the FAS-FAS ligand (FASL) or granule-mediated pathways (Chavez-Galan et al. 2009). For the granule-mediated system, cytotoxic lymphocytes deliver cytolytic granules containing perforin, granzymes, and granulysin to the target cell. Granzyme B cleaves procaspases to their active forms, leading to activation of the caspase cascade and apoptosis. In experiments performed to assess the effect of mouse SC-conditioned media on granzyme B activity, SERPINA3N, a novel granzyme B inhibitor, was discovered (Sipione et al. 2006). This was the first demonstration of a secreted granzyme B inhibitor. Moreover, SCs have been shown to express protease inhibitor-9 (SERPINB9, PI9; Bladergroen et al. 2001, Hirst et al. 2001). PI9 is a cytoplasmic inhibitor of granzymes $\mathrm{A}$ and $\mathrm{B}$, and recently it has been found that PI9 can also inhibit FAS-FASL-induced apoptosis (Cunningham et al. 2007).

In the FAS-FASL pathway, binding of the FAS receptor by FASL initiates caspase activation and apoptotic cell death. The importance of this pathway was initially investigated in a report showing that mouse testicular cells expressing FASL survived following allogeneic transplantation, whereas testicular cells isolated from donors lacking functional FASL were rapidly rejected (Bellgrau et al. 1995). Similarly, allogeneic islets were protected when transplanted with either SCs expressing FASL or muscle cells genetically engineered to produce FASL (Lau et al. 1996, Korbutt et al. 1997). Thus, it was hypothesized that SCs expressing FASL interact with FAS bearing lymphocytes leading to the death of the lymphocytes via apoptosis. Further support for this idea came from a study that demonstrated apoptosis of infiltrating cells within the SC/islet co-grafts (Takeda et al. 1998). In this report, wild-type SCs co-transplanted with allogeneic islets resulted in prolonged graft survival. In contrast, allogeneic islets co-grafted with SCs isolated from donors lacking functional FASL and transplanted into wild-type mice or co-grafted with wild-type SCs transplanted into mice with a defect in FAS were rejected in the same time frame as islets transplanted alone. Histological examination of the transplanted tissue detected FASL only in the grafts that received wild-type SCs. Consistently, apoptosis and FAS expression of the infiltrating mononuclear cells were present in the surviving SC/islet co-grafts (Takeda et al. 1998), thus suggesting the FAS-FASL system may be important for SCs immune privilege.

While intriguing, the role of the FAS-FASL pathway in immune privilege has become contentious. Expression of FASL in transgenic or genetically modified islets did not protect endogenous or allogeneic islets from immune rejection (Allison et al. 1997, Kang et al. 1997). Instead, FASL expression led to a proinflammatory environment and contributed to the dense neutrophilic infiltration associated with islet destruction. Furthermore, use of a neutralizing antibody to FASL in NOD mice that had received SC/islet co-grafts failed to significantly diminish the survival of the islets 
(Korbutt et al. 2000, Suarez-Pinzon et al. 2000). In this autoimmune model, high expression of FASL by the SCs was associated with neutrophil recruitment in the rejected grafts, while FASL was transient and nearly undetectable by the end of the study in the successful grafts.

Making the issue even more complicated, it is now known that FAS and FASL also exist in soluble forms, sFAS and sFASL. Interestingly, when SCs were incubated with low levels of tumor necrosis factor $\alpha$ and IFNG, sFAS expression was induced which led to protection from apoptosis (Riccioli et al. 2000). In addition, there are several regulatory steps in the activation of the FAS-FASL pathway including the production of decoy receptors, inhibitors, cytokines, and growth factors that can prevent FAS-mediated killing (Choi \& Benveniste 2004). The role of these factors in the SC is unclear and requires further study. However, it has been proposed that the combination of several regulatory factors at immune-privileged sites (see example of FASL and TGFB described in the next section) could explain the discrepancy in the role of FASL in transplantation survival. Ferguson et al. (2002), pointed out that sites with endogenous FASL expression, like the immuneprivileged anterior chamber of the eye, do not lead to inflammation, but instead are anti-inflammatory. However, when the expression of FASL was engineered, the result was an inflammatory response and graft destruction. This suggests interactions between multiple factors that are present at immune-privileged sites, but not at other sites, are important for the appropriate regulation of the FAS-FASL pathway, which allow this pathway to participate in creating an immuneprivileged environment.

\section{Interaction between multiple immune-modulating factors}

SCs express several cytokines that can produce proinflammatory and anti-inflammatory effects, as well as numerous other factors that may modulate the immune response; for example, IL1A, IL6, macrophage migration inhibitory factor, IFNA, IFNB, IFNG, TGFB1, activin, $\mathrm{C}-\mathrm{C}$ motif chemokine ligand 5 (CCL5), CCL2/monocyte chemoattractant protein-1, C-X-C motif chemokine ligand 1 (CXCL1), CXCL10, fractalkine (CX3CL1), and Toll like receptors 2-6 (Hedger \& Meinhardt 2003, Bhushan et al. 2009, Guazzone et al. 2009). It is likely a complex interaction between several immune-modulating molecules may be responsible for SC immunoprotection. For instance, subcutaneous transplantation of a colon carcinoma cell line stably expressing FASL resulted in neutrophil recruitment and rapid rejection (Chen et al. 1998). In contrast, when these cells were engineered to also express TGFB the grafts survived. The authors hypothesized the protection was due to TGFB induced inhibition of p38 MAP kinase which in turn prevents FASL-induced neutrophil cytotoxicity. Thus, production of both TGFB and FASL by SCs may synergistically promote cell survival by inhibiting inflammation and inducing apoptosis of lymphocytes. Interactions between these and other factors in controlling the immune-privileged environment should be the subject of future study.

\section{Alternative strategies: cell therapy}

As already mentioned, SCs have the ability to survive for extended periods of time when transplanted across immunological barriers. Interestingly, the ability of SCs to survive transplantation even surpasses their ability to protect co-transplanted cells. For example, when allogeneic SC were co-transplanted with islets, over $90 \%$ of the grafts contained large numbers of surviving SCs, while allogeneic islet graft survival was prolonged $60 \%$ of the time (Dufour et al. 2008a). This increased survival suggests SCs could be exploited as a vehicle to deliver therapeutic products like insulin or dopamine for type 1 diabetes or Parkinson's disease respectively. This idea was first explored by Dufour et al. (2004), SCs were isolated from green fluorescent protein (GFP) transgenic mice and transplanted allogeneically under the kidney capsule of $\mathrm{BALB} / \mathrm{C}$ mice. Engineered SCs survived and continued to express GFP throughout the duration of the study (60 days). This study verified that genetically engineered SCs maintain their immune-privileged status, but it did not examine their ability to express a clinically relevant factor.

Another example of genetically engineered SCs came from the work of Trivedi et al. (2006) in which SCs were modified with a recombinant adenoviral vector expressing enhanced GFP and a human trophic factor, neurotrophin-3. The modified SCs, implanted as allografts into the acutely injured spinal cord, survived for at least 42 days. However, significant levels of neurotrophin-3 were produced for only 3 days after grafting (Trivedi et al. 2006).
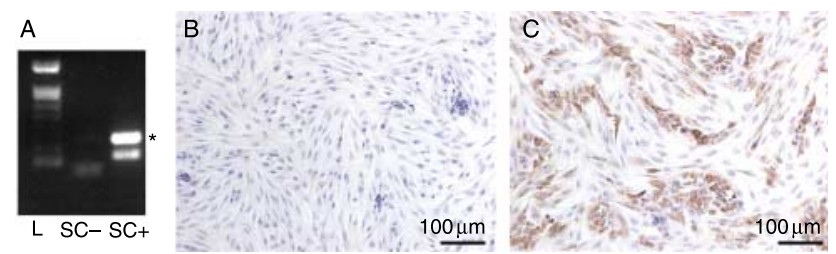

Figure 2 In vitro expression of insulin by adenovirus-transduced neonatal porcine Sertoli cells. SCs isolated from neonatal pigs were cultured overnight as a monolayer with DMEM plus $10 \%$ fetal bovine serum, transduced with the adenoviral vector containing furinmodified human insulin cDNA at a multiplicity of infection of 0 $(\mathrm{A}(\mathrm{SC}-)$ and $\mathrm{B})$ or $100(\mathrm{~A}(\mathrm{SC}+)$ and $\mathrm{C})$ and collected after $48 \mathrm{~h}$ for immunohistochemistry (B and $C$ ) or $72 \mathrm{~h}(\mathrm{~A})$ for RNA isolation. (A) RT-PCR was performed for insulin (asterisk, $263 \mathrm{bp}$ ). Lane 1 is the $1 \mathrm{~kb}$ Plus DNA ladder (Invitrogen). (B and C) Slides were collected after 2 days, fixed with $1 \%$ paraformaldehyde and immunostained for insulin. All sections were counterstained with hematoxylin. 


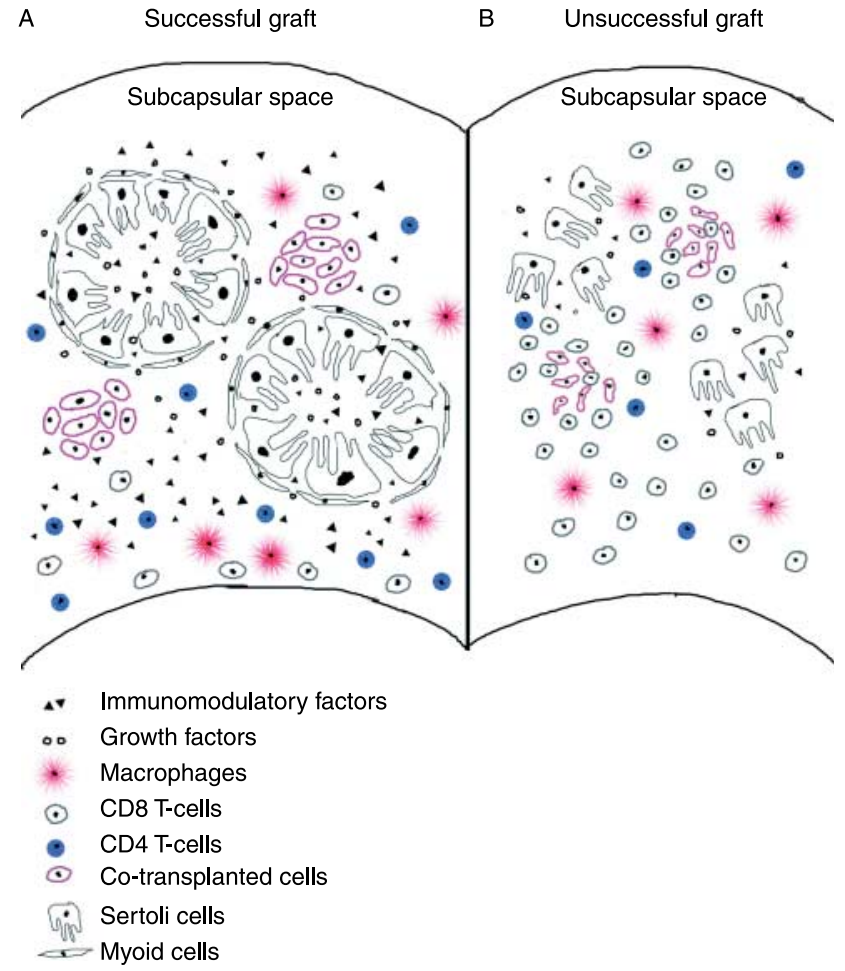

Figure 3 Model comparing successful and unsuccessful Sertoli cell co-transplantation grafts. (A) Successful SC co-grafts. The SCs were arranged in tubule-like structures and secreted immunomodulatory factors that inhibited the migration and altered the phenotype of the infiltrating immune cells, ultimately creating an immune-privileged environment that protected the transplanted cells. (B) Unsuccessful SC co-grafts. SCs in the rejected grafts were randomly arranged and infiltrating immune cells flooded the graft site leading to destruction of the transplanted cells.

More recently, the possibility of engineering SCs to produce a biologically active and therapeutically relevant factor was examined. SCs, transduced with a recombinant adenoviral vector containing furinmodified human insulin cDNA, were transplanted underneath the kidney capsule of diabetic SCID mice and blood glucose levels were measured (J Dufour, unpublished observations). These SCs produced insulin mRNA and protein (Fig. 2) and secreted mature insulin at levels capable of normalizing blood glucose levels. However, due to the epichromosomal nature of the adenoviral vector, the production of insulin was transient. Nevertheless, these studies suggest that immune-privileged SCs modified genetically to secrete clinically relevant proteins have a practical therapeutic potential.

\section{Conclusion}

The immunoprotective nature of SCs has been presented in a number of studies in vitro and in vivo with a focus on their ability to immunoprotect allo- and xenogeneic cellular grafts transplanted in the testis and at sites outside of the testis. The use of these immune-privileged SCs may allow for successful cell engraftment without the need for chronic immunosuppression therapy. While it is clear from rodent studies that SCs can prolong the survival of several different tissues after transplantation, the protective ability is variable. This is likely due to the existence of a complex SC immunemodulatory mechanism involving the interaction of multiple parameters including direct effects on the engrafted cells, effects at the transplantation site, and effects on the host's systemic immune system (Fig. 3). Therefore, a more in-depth understanding of the factors and conditions needed for optimal SC immunoprotection, especially in large animals, will be required before this novel technology can be used clinically.

\section{Declaration of interest}

The authors declare that there is no conflict of interest that could be perceived as prejudicing the impartiality of the research reported.

\section{Funding}

This work was supported in part by the American Diabetes Association (1-06-JF-13) and Texas Tech University Health Sciences Center School of Medicine Seed Grant Program.

\section{Acknowledgements}

We would like to thank Dr Kwan Hee Kim, Dr Charles Faust, Karen Seeberger, and Emily Dyson for critically reading this manuscript.

\section{References}

Akimaru K, Stuhlmiller GM \& Seigler HF 1981 Allotransplantation of insulinoma into the testis of diabetic rats. Transplantation 32 227-232.

Allison J, Georgiou HM, Strasser A \& Vaux DL 1997 Transgenic expression of CD95 ligand on islet beta cells induces a granulocytic infiltration but does not confer immune privilege upon islet allografts. PNAS 94 3943-3947.

Bailey R \& Griswold MD 1999 Clusterin in the male reproductive system: localization and possible function. Molecular and Cellular Endocrinology 151 17-23.

Barker CF \& Billingham RE 1977 Immunologically privileged sites. Advances in Immunology 25 1-54.

Bellgrau D, Gold D, Selawry H, Moore J, Franzusoff A \& Duke RC 1995 A role for CD95 ligand in preventing graft rejection. Nature 377 630-632.

Bhushan S, Schuppe HC, Tchatalbachev S, Fijak M, Weidner W, Chakraborty T \& Meinhardt A 2009 Testicular innate immune defense against bacteria. Molecular and Cellular Endocrinology 306 37-44.

Bladergroen BA, Strik MC, Bovenschen N, van Berkum O, Scheffer GL, Meijer CJ, Hack CE \& Kummer JA 2001 The granzyme B inhibitor, protease inhibitor 9, is mainly expressed by dendritic cells and at immune-privileged sites. Journal of Immunology 166 3218-3225.

Cameron DF, Whittington K, Schultz RE \& Selawry HP 1990 Successful islet/abdominal testis transplantation does not require Leydig cells. Transplantation 50 649-653.

Chavez-Galan L, Arenas-Del Angel MC, Zenteno E, Chavez R \& Lascurain R 2009 Cell death mechanisms induced by cytotoxic lymphocytes. Cellular \& Molecular Immunology 6 15-25. 
Chen JJ, Sun Y \& Nabel GJ 1998 Regulation of the proinflammatory effects of Fas ligand (CD95L). Science 282 1714-1717.

Choi C \& Benveniste EN 2004 Fas ligand/Fas system in the brain: regulator of immune and apoptotic responses. Brain Research Reviews 44 65-81.

Cunningham TD, Jiang X \& Shapiro DJ 2007 Expression of high levels of human proteinase inhibitor 9 blocks both perforin/granzyme and Fas/Fas ligand-mediated cytotoxicity. Cellular Immunology 245 32-41.

De Cesaris P, Filippini A, Cervelli C, Riccioli A, Muci S, Starace G, Stefanini M \& Ziparo E 1992 Immunosuppressive molecules produced by Sertoli cells cultured in vitro: biological effects on lymphocytes. Biochemical and Biophysical Research Communications $\mathbf{1 8 6}$ 1639-1646.

Dufour JM, Rajotte RV, Kin T \& Korbutt GS 2003a Immunoprotection of rat islet xenografts by cotransplantation with Sertoli cells and a single injection of antilymphocyte serum. Transplantation 75 1594-1596.

Dufour JM, Rajotte RV, Korbutt GS \& Emerich DF 2003b Harnessing the immunomodulatory properties of Sertoli cells to enable xenotransplantation in type I diabetes. Immunological Investigations 32 275-297.

Dufour JM, Rajotte RV, Seeberger K, Kin T \& Korbutt GS 2003c Long-term survival of neonatal porcine Sertoli cells in non-immunosuppressed rats. Xenotransplantation 10 577-586.

Dufour JM, Hemendinger R, Halberstadt CR, Gores P, Emerich DF, Korbutt GS \& Rajotte RV 2004 Genetically engineered Sertoli cells are able to survive allogeneic transplantation. Gene Therapy 11 694-700.

Dufour JM, Hamilton M, Rajotte RV \& Korbutt GS 2005 Neonatal porcine Sertoli cells inhibit human natural antibody-mediated lysis. Biology of Reproduction 72 1224-1231.

Dufour JM, Dass B, Halley KR, Korbutt GS, Dixon DE \& Rajotte RV 2008a Sertoli cell line lacks the immunoprotective properties associated with primary Sertoli cells. Cell Transplantation 17 525-534.

Dufour JM, Lord SJ, Kin T, Rayat GR, Dixon DE, Bleackley RC, Korbutt GS \& Rajotte RV 2008b Comparison of successful and unsuccessful islet/Sertoli cell cotransplant grafts in streptozotocin-induced diabetic mice. Cell Transplantation 16 1029-1038.

Dym M \& Fawcett DW 1970 The blood-testis barrier in the rat and the physiological compartmentation of the seminiferous epithelium. Biology of Reproduction 3 308-326.

Ferguson J \& Scothorne RJ 1977a Extended survival of pancreatic islet allografts in the testis of guinea-pigs. Journal of Anatomy 124 1-8.

Ferguson J \& Scothorne RJ 1977b Further studies on the transplantation of isolated pancreatic islets. Journal of Anatomy 124 9-20.

Ferguson TA, Green DR \& Griffith TS 2002 Cell death and immune privilege. International Reviews of Immunology 21 153-172.

Gores PF, Hayes DH, Copeland MJ, Korbutt GS, Halberstadt C, Kirkpatrick SA \& Rajotte RV 2003 Long-term survival of intratesticular porcine islets in nonimmunosuppressed beagles. Transplantation $\mathbf{7 5}$ 613-618.

Griswold MD 1998 The central role of Sertoli cells in spermatogenesis. Seminars in Cell and Developmental Biology 9 411-416.

Guazzone VA, Jacobo P, Theas MS \& Lustig L 2009 Cytokines and chemokines in testicular inflammation: a brief review. Microscopy Research and Technique 72 620-628.

Head JR \& Billingham RE 1985 Immune privilege in the testis. II. Evaluation of potential local factors. Transplantation 40 269-275.

Head JR, Neaves WB \& Billingham RE 1983a Immune privilege in the testis. I. Basic parameters of allograft survival. Transplantation 36 423-431.

Head JR, Neaves WB \& Billingham RE $1983 b$ Reconsideration of the lymphatic drainage of the rat testis. Transplantation 35 91-95.

Hedger MP \& Meinhardt A 2003 Cytokines and the immune-testicular axis. Journal of Reproductive Immunology 58 1-26.

Hirst CE, Buzza MS, Sutton VR, Trapani JA, Loveland KL \& Bird PI 2001 Perforin-independent expression of granzyme $B$ and proteinase inhibitor 9 in human testis and placenta suggests a role for granzyme B-mediated proteolysis in reproduction. Molecular Human Reproduction 7 $1133-1142$.

Kang SM, Schneider DB, Lin Z, Hanahan D, Dichek DA, Stock PG \& Baekkeskov S 1997 Fas ligand expression in islets of Langerhans does not confer immune privilege and instead targets them for rapid destruction. Nature Medicine 3 738-743.

Korbutt GS, Elliott JF \& Rajotte RV 1997 Cotransplantation of allogeneic islets with allogeneic testicular cell aggregates allows long-term graft survival without systemic immunosuppression. Diabetes 46 317-322.
Korbutt GS, Suarez-Pinzon WL, Power RF, Rajotte RV \& Rabinovitch A 2000 Testicular Sertoli cells exert both protective and destructive effects on syngeneic islet grafts in non-obese diabetic mice. Diabetologia $\mathbf{4 3}$ 474-480.

Lau HT, Yu M, Fontana A \& Stoeckert CJ Jr 1996 Prevention of islet allograft rejection with engineered myoblasts expressing FasL in mice. Science 273 109-112.

Lee HM, Lim HG, Oh BC, Park CS, Lee DS \& Lee JR 2007a Systemic immune modulation using chemokine receptor 7 expressing porcine Sertoli cells. Xenotransplantation 14 619-626.

Lee HM, Oh BC, Lim DP, Lee DS, Cho J, Lee G \& Lee JR $2007 b$ Role of complement regulatory proteins in the survival of murine allo-transplanted Sertoli cells. Journal of Korean Medical Science 22 277-282.

Lim HG, Lee HM, Oh BC \& Lee JR 2009 Cell-mediated immunomodulation of chemokine receptor 7 -expressing porcine Sertoli cells in murine heterotopic heart transplantation. Journal of Heart and Lung Transplantation $\mathbf{2 8}$ $72-78$.

Luca G, Calafiore R, Basta G, Ricci M, Calvitti M, Neri L, Nastruzzi C, Becchetti E, Capitani S, Brunetti P et al. 2001 Improved function of rat islets upon co-microencapsulation with Sertoli's cells in alginate/ poly-L-ornithine. AAPS PharmSciTech 2 E15.

Mead R, Hinchliffe SJ \& Morgan BP 1999 Molecular cloning, expression and characterization of the rat analogue of human membrane cofactor protein (MCP/CD46). Immunology 98 137-143.

Naji A \& Barker CF 1976 The influence of histocompatibility and transplant site on parathyroid allograft survival. Journal of Surgical Research $\mathbf{2 0}$ 261-267.

O'Rand MG \& Romrell LJ 1977 Appearance of cell surface auto- and isoantigens during spermatogenesis in the rabbit. Developmental Biology 55 347-358.

Rahman TM, Diakanov I, Selden C \& Hodgson H 2005 Co-transplantation of encapsulated HepG2 and rat Sertoli cells improves outcome in a thioacetamide induced rat model of acute hepatic failure. Transplant International 18 1001-1009.

Riccioli A, Starace D, D'Alessio A, Starace G, Padula F, De Cesaris P, Filippini A \& Ziparo E 2000 TNF-alpha and IFN-gamma regulate expression and function of the Fas system in the seminiferous epithelium. Journal of Immunology 165 743-749.

Russell L 1977 Movement of spermatocytes from the basal to the adluminal compartment of the rat testis. American Journal of Anatomy $\mathbf{1 4 8}$ 313-328.

Russell LD \& Griswold MD 1993 The Sertoli Cell. Clearwater, FL: Cache River Press.

Russell LD, Ettlin RA, Sinha Hikim AP \& Clegg ED 1990 Histological and Histopathological Evaluation of the Testis. Clearwater, FL: Cache River Press.

Sanberg PR, Borlongan CV, Saporta S \& Cameron DF 1996 Testis-derived Sertoli cells survive and provide localized immunoprotection for xenografts in rat brain. Nature Biotechnology 14 1692-1695.

Selawry HP 1994 Islet transplantation to immunoprivileged sites. In Pancreatic Islet Transplantation: Immunomodulation of Pancreatic Islets, pp 75-86. Eds RP Lanza \& WL Chick. Austin, TX: Landes/CRC Press.

Selawry HP \& Cameron DF 1993 Sertoli cell-enriched fractions in successful islet cell transplantation. Cell Transplantation 2 123-129.

Selawry HP \& Whittington K 1984 Extended allograft survival of islets grafted into intra-abdominally placed testis. Diabetes 33 405-406.

Selawry HP \& Whittington KB 1988 Prolonged intratesticular islet allograft survival is not dependent on local steroidogenesis. Hormone and Metabolic Research 20 562-565.

Selawry HP, Kotb M, Herrod HG \& Lu ZN 1991 Production of a factor, or factors, suppressing IL-2 production and T cell proliferation by Sertoli cell-enriched preparations. A potential role for islet transplantation in an immunologically privileged site. Transplantation 52 846-850.

Shamekh R, El-Badri NS, Saporta S, Pascual C, Sanberg PR \& Cameron DF 2006 Sertoli cells induce systemic donor-specific tolerance in xenogenic transplantation model. Cell Transplantation 15 45-53.

Sipione S, Simmen KC, Lord SJ, Motyka B, Ewen C, Shostak I, Rayat GR, Dufour JM, Korbutt GS, Rajotte RV et al. 2006 Identification of a novel human granzyme B inhibitor secreted by cultured Sertoli cells. Journal of Immunology 177 5051-5058. 
Suarez-Pinzon W, Korbutt GS, Power R, Hooton J, Rajotte RV \& Rabinovitch A 2000 Testicular Sertoli cells protect islet beta-cells from autoimmune destruction in NOD mice by a transforming growth factorbeta1-dependent mechanism. Diabetes 49 1810-1818.

Takeda Y, Gotoh M, Dono K, Nishihara M, Grochowiecki T, Kimura F, Yoshida T, Ohta Y, Ota H, Ohzato H et al. 1998 Protection of islet allografts transplanted together with Fas ligand expressing testicular allografts. Diabetologia 41 315-321.

Trivedi AA, Igarashi T, Compagnone N, Fan X, Hsu JY, Hall DE, John CM \& Noble-Haeusslein LJ 2006 Suitability of allogeneic Sertoli cells for ex vivo gene delivery in the injured spinal cord. Experimental Neurology 198 88-100.

Tung PS \& Fritz IB 1978 Specific surface antigens on rat pachytene spermatocytes and successive classes of germinal cells. Developmental Biology 64 297-315.

Valdes-Gonzalez RA, Dorantes LM, Garibay GN, Bracho-Blanchet E, Mendez AJ, Davila-Perez R, Elliott RB, Teran L \& White DJ 2005 Xenotransplantation of porcine neonatal islets of Langerhans and Sertoli cells: a 4-year study. European Journal of Endocrinology 153 419-427.

Valdes-Gonzalez RA, White DJ, Dorantes LM, Teran L, GaribayNieto GN, Bracho-Blanchet E, Davila-Perez R, Evia-Viscarra L, Ormsby CE, Ayala-Sumuano JT et al. 2007 Three-yr follow-up of a type 1 diabetes mellitus patient with an islet xenotransplant. Clinical Transplantation 21 352-357.

Wang DZ, Skinner S, Elliot R, Escobar L, Salto-Tellez M, Garkavenko O, Khoo A, Lee KO, Calne R \& Isaac JR 2005 Xenotransplantation of neonatal porcine islets and Sertoli cells into nonimmunosuppressed streptozotocin-induced diabetic rats. Transplantation Proceedings 37 470-471.
Whitmore WF \& Gittes RF 1977 Studies on the prostate and testis as immunologically privileged sites. Cancer Treatment Reports $\mathbf{6 1}$ 217-222.

Whitmore WF III, Karsh L \& Gittes RF 1985 The role of germinal epithelium and spermatogenesis in the privileged survival of intratesticular grafts. Journal of Urology 134 782-786.

Willing AE, Sudberry JJ, Othberg AI, Saporta S, Poulos SG, Cameron DF, Freeman TB \& Sanberg PR 1999 Sertoli cells decrease microglial response and increase engraftment of human hNT neurons in the hemiparkinsonian rat striatum. Brain Research Bulletin $\mathbf{4 8}$ 441-444.

Wyatt CR, Law L, Magnuson JA, Griswold MD \& Magnuson NS 1988 Suppression of lymphocyte proliferation by proteins secreted by cultured Sertoli cells. Journal of Reproductive Immunology 14 27-40.

Yang H \& Wright JR Jr 1999 Co-encapsulation of Sertoli enriched testicular cell fractions further prolongs fish-to-mouse islet xenograft survival. Transplantation 67 815-820.

Yule TD, Montoya GD, Russell LD, Williams TM \& Tung KS 1988 Autoantigenic germ cells exist outside the blood-testis barrier. Journal of Immunology 141 1161-1167.

Received 28 August 2009

First decision 22 October 2009

Revised manuscript received 6 November 2009

Accepted 8 December 2009 